\title{
CORRIGENDUM
}

\section{The way forward in HCV treatment — finding the right path}

Michael P. Manns, Graham R. Foster, Jürgen K. Rockstroh, Stefan Zeuzem, Fabien Zoulim \& Michael Houghton

Nature Reviews Drug Discovery 6, 991-1000 (December 2007) | doi: 10.1038/nrd2411

On page 996 , in the first paragraph of the right-hand column, which discusses studies with boceprevir, pegIFN- $\alpha 2$ a was stated as the pegylated interferon that patients had previously failed in order to be considered non-responders. This is not accurate since they could have failed pegIFN- $\alpha 2$ a or pegIFN- $\alpha 2 b$. In addition, pegIFN- $\alpha 2$ a was stated as the pegylated interferon being used in combination with boceprevir in Phase I and Phase II studies. However, the pegylated interferon used is pegIFN- $\alpha 2 b$.

The statements should read as follows:

A dose-ranging study of boceprevir (100-400 mg twice a day) in patients with HCV genotype 1 that had previously failed pegIFN- $\alpha 2$ therapy indicates that this protease inhibitor has dose-related antiviral activity as monotherapy. A Phase lb 14-day study of boceprevir ( 200 or $400 \mathrm{mg}$ three times daily) administered in combination with pegIFN- $\alpha 2 \mathrm{~b}(1.5 \mu \mathrm{g}$ per kg weekly) demonstrated a dose-response relationship in non-responder patients with HCV genotype 1. Mean maximum $\log _{10}$ reductions in HCV RNA were 2.45 and 2.88 for 200 and $400 \mathrm{mg}$ boceprevir plus pegIFN- $\alpha 2 \mathrm{~b}$, respectively ${ }^{49}$, and the combination of agents provided greater antiviral activity than either drug as monotherapy. Boceprevir $800 \mathrm{mg}$ three times a day is currently being evaluated in combination with pegIFN- $\alpha 2 b$ and ribavirin in a Phase Il trial of non-responders. A further Phase II trial of boceprevir $800 \mathrm{mg}$ three times a day in combination with pegIFN- $\alpha 2 \mathrm{~b}$ and ribavirin has also been initiated in treatment-naive patients. Recent preliminary results from this so-called SPRINT (Serine Protease Inhibitor Therapy) study are comparable to the two telapravir Phase Il studies in treatment naive patients ${ }^{113-115}$. 